\title{
DAS PRIMEIRAS ÀS OUTRAS ESTÓRIAS: ADAPTAÇÃO, MANUTENÇÃO E ALTERAÇÃO DAS FORMAS SEMIÓTICAS
}

\section{DES PRÉMIÈRES HISTOIRES À D'AUTRES HISTOIRES: ADAPTATION, MAINTENANCE ET ALTERATION DES FORMES SÉMIOTIQUES}

\author{
Vera Lucia Rodella Abriata \\ UNIFRAN - Universidade de Franca \\ Naiá Sadi Câmara \\ UNIFRAN - Universidade de Franca \\ Matheus Nogueira Schwartzmann \\ UNIFRAN - Universidade de Franca
}

\begin{abstract}
RESUMO: Este artigo tem por objetivo discutir determinadas alterações empreendidas em cenas de Primeiras estórias, de João Guimarães Rosa, no processo de adaptação dessa obra para o texto fílmico Outras estórias, de Pedro Bial. Para tanto, discute-se a natureza da mudança de suporte, na esteira dos estudos de base greimasiana, observando certas construções de sentido que se recriam nesse processo de transcodificação. Utiliza-se, desse modo, a noção de adaptação enquanto forma de tradução/transcodificação, isto é, uma interpretação que se realiza como enunciado segundo que deve manter certa equivalência em relação ao enunciado primeiro. $O$ texto aponta também para as noções de recursividade e desdobramento, formas de uma tipologia textual que podem dar conta das alterações da expressão na passagem do texto verbal rosiano ao audiovisual de Pedro Bial. Por fim, pretende-se ainda apontar certos encadeamentos figurativos e temáticos que se organizam nos dois textos e que permitem a percepção da supressão do estado de aparente loucura de Liojorge no filme, o qual é enunciado no texto verbal, e, por sua vez, a reiteração do estado de coragem do ator, já presente no texto rosiano, em cenas do texto fílmico.
\end{abstract}

PALAVRAS-CHAVE: Semiótica; Adaptação; João Guimarães Rosa.

RÉSUMÉ: Cette analyse met en cause les modifications aménagées dans des scènes de Primeiras Histórias [Premières histoires], de João Guimarães Rosa, au cours du processus de son adaptation vers le texte filmique Outras Histórias [D'autres histoires], de Pedro Bial. On part d'une discussion à propos de la nature du changement de support, selon la perspective des études établies par la sémiotique greimassienne, tout en observant les constructions de sens qui sont (r)élaborées dans ce processus de trans-codification. On prend ici donc la notion d'adaptation comme forme de traduction/trans-codification, c'est à dire, une interprétation réalisée comme énoncé secondaire qui doit maintenir quelque équivalence par rapport à l'énoncé premier. Ce travail renvoie aussi aux notions de récursivité et déploiement, comme des formes d'une typologie textuel qui peut re ndre compte des modifications de l'expression suscitées pendant le passage du verbal à l'audiovisuel. Finalement, on cherche démontrer quelques configurations figuratifs et thématiques qui sont disposées dans les deux textes et qui révèlent, d'un coté, la suppression dans le film de l'état apparent de folie de Liojorge, ce que dans le texte verbal est visiblement énoncé, et de l'autre coté, la réitération et la mise en relief, dans le texte audiovisuel, de son état de courage déjà présent dans le texte verbal de Rosa. 
MOTS-CLÉS: Sémiotique; Adaptation; João Guimarães Rosa.

\title{
O alto grau da significação: uma obra poética
}

\begin{abstract}
Precisa-se, assim, o estatuto paradoxal do discurso poético: sintaticamente, é um discurso abstrato, comparável por isso aos discursos praticados na lógica e nas matemáticas; semanticamente, é um discurso figurativo e, como tal, garantia de uma forte eficiência comunicativa. Não surpreende, pois, que o efeito de sentido que dele se depreende seja, como no caso do discurso sagrado, o da verdade
\end{abstract}

GREIMAS; COURTÈS, 2008, p.375

João Guimarães Rosa (1908-1967) é reconhecidamente um dos maiores mestres da prosa brasileira. Sua obra, que ainda hoje se situa na vanguarda da narrativa brasileira, tem como marca maior a forma como o autor lapida sua linguagem, dando à palavra, assim como se faz a uma gema, facetas múltiplas, de onde parte um feixe de significações. $\mathrm{O}$ alto grau de significação que Rosa dá à sua prosa a eleva naturalmente ao mais alto patamar a que chega a literatura. Isso se tomarmos obviamente como base a noção de literatura como alteração da linguagem, como novidade, como invenção e gesto artístico por natureza. Em Ezra Pound, por exemplo, pode-se encontrar justamente uma definição de literatura que facilmente recobre a obra rosiana: "literatura é linguagem carregada de significado [...] é novidade que permanece novidade" (POUND, 1997, p. 32-33).

Mantendo-se nos trilhos da novidade, portanto, Rosa anula intencionalmente as fronteiras entre narrativa, lírica e drama - as forças genéricas que regem os textos -, o que, ao lado da abordagem que faz das dimensões pré-conscientes do ser humano e do tênue limite que instaura entre realidade e irrealidade, o aproxima de outros grandes autores como Julio Cortazar e James Joyce, Jorge Luiz Borges e Ítalo Calvino.

As suas histórias correm como fábulas, formas arquetípicas de mitos originários que, para além de revelar uma visão global da existência, próxima de uma espécie de materialismo religioso, e por isso panteísta, fundem em uma única, e paradoxalmente plural, realidade, o Homem, a Natureza, o Bem e o Mal, o Divino e o Demoníaco, o Uno e o Múltiplo, segundo Alfredo Bosi (2006, p.431).

Desse modo, vê-se que embora a linguagem na obra rosiana seja altamente inovadora do ponto de vista de sua forma, seus temas, seu imaginário, têm como fonte as mais antigas tradições, estando mesmo ancorada na tradição oral. Bosi a isso faz menção quando afirma que "a narrativa rosiana, que parece a tantos ardilosamente moderna e até mesmo experimental pela ousadia das soluções formais, realiza, com as artimanhas da linguagem, uma nova tradução do pensamento arcaico-popular" (1988, p. 23).

Isso quer dizer que o imaginário arcaico-popular surge ressignificado na prosa de Rosa, já que ao reconstruí-lo em seus textos, entretece-o a discursos outros, dando-lhe nova roupagem. Em "Pirlimpsiquice", conto de Primeiras estórias, por exemplo, na teatralização, pode-se entrever ainda um discurso marcado por uma tomada de posição psicanalítica, em que o drama encenado passa a ser o drama de um sujeito, de uma psiqu(ice) muito particular, que tem no medo, na vergonha, formas identitárias pregnantes. Muitas vezes, recorrendo a figuras animais, é o discurso filosófico que emerge, trazendo consigo o trágico que subsiste à vida, como ocorre em "Conversa de bois", conto de Sagarana. Em outros momentos, tem-se no 
intertexto a riqueza da atualização do universo arcaico-popular: lançam-se luzes sobre a mitologia clássica atualizando arquétipos míticos, ou sobre a literatura universal, instaurando um ponto de vista metafísico sobre o sertão mineiro. O sertanejo surge assim cingido de erudição, e o seu sertão perde qualquer limite.

Em entrevista a Günter Lorenz, um de seus tradutores para o alemão, Rosa afirma que em seu sertão fala-se "não do ponto de vista filológico e sim do metafísico [...] a língua de Goethe, Dostoiévski, Flaubert" (LORENZ, 1983, p. 86). Tal ideia permeia toda a obra de Rosa e pode ser recuperada, por exemplo, de uma pequena passagem de seu Grande sertão: veredas, na voz de Riobaldo, quando o jagunço, ao explicar a dimensão do sertão, observa que "o sertão está em toda parte" (ROSA, 1976, p. 9). Tem-se, nesse exemplo, a noção exata do que ocorre na obra: longe de ser uma mimetização da realidade ou da cultura popular, sua obra vale-se dessa realidade geográfica, social e/ou política, transcendendo o local para atingir o universal ao criar um universo mitopoético. No texto de Rosa, portanto, ergue-se um sertão atemporal que o filme "Outras Estórias" recria, transmitindo ao enunciatário o efeito de fidelidade ao texto fonte. É o que temos por objetivo apresentar por meio desta análise.

\section{O alto grau de condensação: uma adaptação poética}

É justamente esse sertão, recriado pela linguagem mitopoética de Guimarães Rosa, que Pedro Bial, jornalista e diretor de cinema brasileiro, buscou transpor para o cinema no filme Outras Estórias, de 1999. Tendo como base cinco ${ }^{1}$ dos contos de Primeiras Estórias, livro que Rosa lançou em 1962, o filme recria na tela o universo rosiano. O desafio é grande e arriscado, ainda mais tendo em vista a escolha de Bial de manter fidelidade ao texto verbal rosiano em grande parte do filme Assim, não se observam diálogos naturalizados no texto audiovisual, como se nota frequentemente na televisão e no cinema. Desse modo, as personagens rosianas surgem na tela parecendo declamar trechos dos contos.

Não se vê no filme, portanto, um mimetismo do sertão "real e, ao invés da cor local, tem-se a apreensão da dimensão universal do sertão, por meio da fidelidade à prosa mitopoética de Rosa que o diretor cinematográfico empreendeu.

Neste artigo, pretendemos lançar luz a certas características da adaptação em relação à obra fonte, destacando, essencialmente, (1) a natureza da mudança de suporte - a passagem do verbal ao audiovisual - a qual chamaremos simplesmente tradução ou transcodificação, na esteira dos estudos de base greimasiana e (2) certas construções de sentido que se perdem, se recriam, se convertem, no exercício da manutenção de um mínimo de sentido comum, em novas escolhas isotópicas que têm como base, como iremos mostrar a partir da análise de excertos dos textos, uma leitura do texto rosiano manifestada claramente no texto de Pedro Bial.

\section{Elementos de tradução intersemiótica: adaptar, manter, alterar}

Embora não pretendamos aqui traçar um panorama teórico que dê conta das possíveis definições e abordagens sobre o processo da adaptação, especialmente da adaptação do texto verbal para o texto audiovisual, não podemos deixar de lado as concepções mínimas já esboçadas a esse respeito no seio da teoria greimasiana.

\footnotetext{
${ }^{1}$ Os contos seriam "Os irmãos Dagobé", “A menina de lá", "Nada e a nossa condição", "Soroco sua Mãe, sua Filha" e "Famigerado".
} 
Tanto Greimas e Courtès, no Dicionário de semiótica, quanto outros semioticistas (como Fontanille, por exemplo), têm nos termos tradução (intersemiótica) e transcodificação as definições mínimas do que seria o processo de adaptação, embora não cheguem a tratar desse termo especificamente. Assim, para Greimas e Courtès (2008, p. 508), "entende-se por tradução a atividade cognitiva que opera a passagem de um enunciado dado em outro enunciado considerado equivalente". Ainda segundo o Dicionário de semiótica (2008, p. 509):

É na qualidade de atividade semiótica que a tradução pode ser decomposta em um fazer interpretativo do texto a quo, de um lado, e em um fazer produtor do texto ad quem, de outro. A distinção dessas duas fases permite assim compreender como a interpretação do texto a quo (ou a análise implícita ou explícita desse texto) pode desembocar seja na construção de uma metalinguagem que procura explicá-lo, seja na produção (no sentido forte do termo) do texto ad quem, mais ou menos equivalente - uma decorrência da não-adequação dos dois universos figurativos - ao primeiro.

O que se pode extrair de tal definição é que, em primeiro lugar, a adaptação pode ser tomada como nada mais que uma interpretação do texto fonte. Em segundo lugar, que a adaptação, tomada enquanto um enunciado segundo, deve ser equivalente ao texto fonte. Se, no entanto, temos como objeto de análise uma adaptação que se realiza em um suporte de inscrição diverso do suporte do texto fonte, isto é, se há uma mudança de plano de expressão, temos que pensar em que medida os dois textos podem manter-se equivalentes e em que medida as características do novo suporte alteram (excluindo ou acrescentando elementos) as formas de sentido manifestadas originalmente no texto fonte.

É nessa direção, na afirmação da equivalência entre as formas textuais, que segue também o raciocínio de José Luiz Fiorin quando afirma que "o sentido gerado por um filme não é diferente daquele criado por um romance [e] o que distingue um objeto do outro é apenas a forma de manifestar essa significação, é o plano da expressão" (2008, p. 78). Ou seja, no processo de adaptação, especialmente do texto verbal para o texto audiovisual, certo número de elementos constituintes da sua significação pode desaparecer e outro número pode surgir. Esse fenômeno ocorre graças à natureza dos textos e às práticas de leitura aos quais estão expostos. O texto verbal (literário ou não) depende, essencialmente, para ser lido, que dele se depreenda o sentido a partir da linguagem verbal, que é o plano de expressão que está em jogo nesse caso. Já o texto audiovisual, texto sincrético, coloca em questão não apenas a linguagem verbal, mas outros planos de expressão, como o visual e o sonoro. É, portanto, graças à mudança de plano de expressão - ou de suporte, portanto - que se dão as mudanças, às vezes mais, às vezes menos profundas, entre o texto fonte e o texto adaptado.

Nesse aspecto, temos que estabelecer, durante a análise, o que há de equivalente entre um texto e outro para que os consideremos como forma original e forma adaptada, respectivamente. Primeiramente, temos que pensar na adaptação a mais convencional possível, aquela que se faz crer fiel ao texto original, aquela que se pretende ser justamente uma forma de transcodificação direta e não uma forma dita "livre", em que inúmeras possibilidades de transcri(a)ção seriam possíveis. Devemos pensar então na forma de uma adaptação simples, como aquela em que todos os sentidos são mantidos (ou buscados) em um novo código, em uma nova organização semiótica, sobre um novo suporte de inscrição.

Esse é o caso do nosso objeto de estudo: o texto de Pedro Bial quer-se uma adaptação fiel à obra de origem. E isso se pode perceber não pelas resenhas que tratam do 
filme, nem por quaisquer outros tipos de paratextos, mas por uma perspectiva que parte do próprio texto fílmico, quando observado e comparado ao texto literário. É na escolha pela "recitação", pela "declamação" quase pura dos textos de Rosa, ao longo do filme, que detectamos a busca pela manutenção do texto fonte sobre outro sistema semiótico, o sistema audiovisual. Helena Bonito Couto Pereira (2009, p. 125), retomando outra classificação do processo de adaptação, ao qual ela chama de "transposição", nos acompanha nessa mesma impressão, ao afirmar que se pode inserir "Outras estórias na categoria de adaptação como transposição, pois há um esforço para a preservação da fidelidade em relação à forma, com a reiterada busca por recursos poéticos equivalentes aos da linguagem escrita [e] em relação aos aspectos temáticos ou ideológicos".

De forma geral, embora diversas mudanças sejam perceptíveis na (re)composição de um texto adaptado, aquelas mais visíveis são normalmente as ligadas à ancoragem (espacial, temporal e actorial), e à instauração do ponto de vista. Ou seja, são as estruturas de superfície as que mais se alteram, e as estruturas semionarrativas as que mais se mantêm equivalentes ao texto fonte, já que para que se reconheça a obra adaptada é preciso que o eixo semionarrativo, o Programa narrativo de base, e as estruturas profundas, mantenham-se os mesmos. Desse modo, mesmo em uma adaptação dita livre reconhecer-seão os esquemas eufóricos conjuntivos de aquisição de objeto valor e/ou os esquemas disjuntivos disfóricos, que terão na estrutura fundamental oposições similares, mas que poderão ter no nível discursivo os esquemas figurativos e temáticos os mais diversos.

A forma de representar o mundo natural - isto é, as figuras que são alçadas a essa representação - é, portanto, comumente, o foco das transformações na adaptação, principalmente quando se altera o suporte de inscrição do texto. Assim, muitas das alterações na construção dos enunciados (verbais, verbo-visuais, musicais - sempre acrescidos, pois inexistentes no texto verbal) têm frequentemente origem na própria natureza do suporte de inscrição do texto, que delimita, exige e orienta certas formas de construções de sentido, coagindo o texto à condensação máxima - como em certas vinhetas ou videoclipes -, ou permitindo que se alastre em meio a uma textualidade expandida qualquer, como o caso de séries e minisséries televisivas que traduzem poucas páginas de um conto, por exemplo, em diversos capítulos diários. Tendo assim em vista as propriedades formais do texto, antes de tratarmos das categorias de conteúdo do texto adaptado, procuraremos esboçar qual a natureza da mudança formal que o texto adaptado atualiza em relação ao texto fonte de Rosa.

\section{A condensação textual na adaptação: da recursividade ao desdobramento}

Outras estórias é fruto de uma forma de condensação textual, pois em um único texto, em uma única materialidade formal - a do texto fílmico - cinco textos autônomos de Primeiras estórias foram reunidos: tem-se, assim, textos de dimensões textuais distintas, mas que organizam conteúdos semânticos em certa medida equivalentes. Se pensarmos nas escolhas que poderiam ter sido feitas, nas isotopias que poderiam ter sido adotadas, diante de uma amostragem de vinte e um contos, retomamos facilmente a noção de interpretação, como forma de adaptação, preconizada por Greimas e Courtès: para reunir diversos contos sob uma mesma estruturação, tendo, certamente, portanto, uma mesma estrutura fundamental, e um eixo narrativo de base comum, foi preciso, certamente, diante das vinte e uma Primeiras estórias, fazer uma escolha em que se adotasse um ponto de vista sobre a obra de Guimarães Rosa que fechasse coesa e coerentemente os cinco contos escolhidos. Isto é, foi preciso instaurar uma isotopia de leitura englobante, sobre a qual o texto fílmico se constrói. Mas foi 
preciso, antes, condensar os segmentos narrativos e figurativos, reestruturá-los, em uma sequência textual menor, condensada, que "coubesse" em um único filme longa metragem.

Assim, da busca pela equivalência entre os textos, da tentativa de manutenção do conteúdo do texto fonte, nasce um único texto condensado e coeso. Para que haja tal coesão, no entanto, é preciso que a obra adaptada se apresente, do ponto de vista da sua expressão, sob a forma de um todo analisável, diferentemente dos textos fonte, que não estão organizados como um todo, divididos que estão em contos diversos. Para Jacques Fontanille, são as categorias de expressão do texto, as quais ele chama de tipos textuais, que permitem que se identifique esse todo de sentido organizado, diante do qual é preciso reter "as formas seriais, o caráter isolável [...] ou não isolável [...] das unidades que o constituem e [...] a maneira como o tipo [textual] assegura ou rejeita o fechamento e a homogeneidade do texto" (1999, p. 163). Os tipos textuais podem ser divididos segundo dois critérios diferentes (1) longo vs breve, e (2) aberto vs fechado ${ }^{2}$ (FONTANILLE, 1999, p. 163).

Segundo Matheus Schwartzmann (2009, p.76), "o primeiro dos critérios elencados por Fontanille, que opõe as categorias longo e breve, pressupõe uma norma sociocultural [...] e, por consequência, uma espécie de escala de avaliação exterior (o cânone literário [sendo] um bom exemplo desse tipo de baliza)". Tal critério "acaba por impor também, na escrita, um andamento interno da enunciação que está relacionado, diretamente, à duração da própria história ou do acontecimento narrado" (SCHWARTZMANN, 2009, p.76). No encontro entre a longa duração temporal e a longa "duração"/extensão textual, teríamos, por exemplo, uma organização de tipo "longo", como é o caso da telenovela (seriada), do romance, entre outros.

Já a abertura e o fechamento dos tipos textuais têm bases diretas na relação que há entre o que Fontanille (1999, p. 163) chama de "unidade de leitura" e "unidade de edição". A "unidade de leitura" seria a reunião de constantes do plano da expressão que, se coesas, dão sentido a um "todo organizado". A "unidade de edição" seria justamente o recorte que se faz dessas constantes da expressão. Se a "unidade de edição" coincidir com a "unidade de leitura", a leitura só será possível no interior de determinado recorte, ou melhor, no interior de um todo organizado e, portanto, fechado. No entanto, se as unidades não coincidirem, a leitura não se limitará ao todo organizado, permitindo assim que partes sejam lidas também isoladamente, sendo consideradas abertas.

Segundo Fontanille (1999, p. 163) da combinação entre tais critérios, depreendem-se quatro propriedades distintas de tipos textuais: (1) com o tipo longo/aberto temos a recursividade; (2) com o tipo longo/fechado temos o desdobramento; (3) com o tipo breve/aberto temos a fragmentação e, por fim; (4) com o tipo breve/fechado temos a concentração.

O livro Primeiras estórias, se lido como um conjunto coeso de textos, como uma obra fechada, do ponto de vista de sua extensão, seria longo, pois reúne contos episódicos que têm na coerência temática a sua unidade. Do ponto de vista de sua organização de leitura, seria aberto, pois os contos podem ser lidos independentemente uns dos outros e em ordens diversas, mantendo ainda assim o seu sentido. Desse modo, o texto fonte da adaptação de Pedro Bial, o livro Primeiras estórias, de Rosa, teria como qualidade textual a recursividade, característica dos procedimentos que "permitem a reativação e o encaixe indefinidos das estruturas textuais, dos quais seriam exemplos o romance em diversos volumes, a novela televisiva ou radiofônica, e o poema épico" (SCHWARTZMANN, 2009, p.77).

\footnotetext{
${ }^{2}$ As traduções de Fontanille (1999) são de Matheus Nogueira Schwartzmann.
}

Disponível em: http://seer.fclar.unesp.br/casa 
Outras estórias, o filme, assume uma nova configuração textual, já que a unidade de leitura altera-se, tendo em vista que o filme deve ser lido como um todo se sentido, e não mais de forma episódica. Temos assim no processo de adaptação aqui analisado, uma mudança de um regime textual recursivo para um regime textual baseado no desdobramento — a união de um tipo longo a um fechado — que, mesmo explorando muitas possibilidades de expansão textual, permanece ainda sob o controle de um esquema global, que acaba por "fechar" o texto. Segundo Schwartzmann (2009, p. 78), "o romance policial (cujo enredo gira em torno, normalmente, de um único fato marcante), as peças teatrais, e mesmo o conto popular, seriam exemplares quanto a esse tipo", justamente porque têm em comum, assim como filme ora analisado, um desenrolar narrativo sucessivo, a partir de um fato iniciático comum.

No processo de adaptação que aqui se vê, a alteração do tipo textual permite assim que o conjunto de contos reunido no filme ganhe a coesão na expressão que sustentará a sua coerência em termos de conteúdo: a fragmentação deixa de ser textual (desaparece a divisão em contos, os títulos individuais, as isotopias locais) e passa a ser apenas narrativa e discursiva, isto é, a fragmentação textual dos contos de Primeiras estórias materializa-se nos intermédios, nos encaixes que efetivamente não se encaixam nas Outras estórias, na estruturação de um tempo mnemônico, de idas e vindas que cria o efeito de sentido de verdade humana.

\section{O caso d'Os irmãos Dagobé}

Como apontamos até aqui, no processo de adaptação há dois tipos de alteração das formas semióticas de um texto: a alteração da sua expressão e a alteração do seu conteúdo. Segundo nossa hipótese, tanto uma quanto outra tem como origem as coerções de ordem formal do suporte em que o texto se inscreve: o texto audiovisual, tomado aqui como filme longa metragem, tem assim uma dada duração - regulamentada por uma prática semiótica, que é a prática de exibição/leitura nos cinemas - marcada em termos de horas (em torno de duas horas), o que limita a sua própria existência enquanto texto enunciado. Sua extensão deverá ser aquela que, em duas horas, será possível de ser exibida/lida, continuamente (não se pode pausar a exibição nos cinemas), em um local predeterminado. $\mathrm{O}$ texto verbal, especialmente o de caráter literário, circula em nossa sociedade sob o regime de uma prática de leitura mais livre: os textos literários, impressos em livros (hoje em dia também em e-books) podem ter diversas formas de extensão, pois sua leitura não está correlacionada a uma prática social estanque como a do cinema e sua portabilidade é exponencialmente maior que a do cinema convencional, permitindo a leitura em diversos ambientes, a pausa e a retomada da leitura em momentos diversos, sem que se percam assim elementos do texto enunciado.

Graças a regimes semióticos distintos, portanto, que delimitam a sua existência, cada tipo de texto apresenta uma certa quantidade de elementos que podem estar presentes em um e ausentes noutro. A voz do narrador, por exemplo, no cinema convencional, é sempre refutada, e outros elementos verbo-visuais e sonoros serão enunciados para substituí-la. As descrições figurativas permitem ampla reprodução visual, mas as de caráter psicoafetivo (medo, ansiedade, covardia, coragem, loucura) podem distanciar-se muito, no texto audiovisual, daquelas construídas no texto verbal. Enfim, no processo de adaptação há sempre algo que se perde e algo que se cria de novidade, graças à tradução entre os sistemas semióticos. 
Para este trabalho, focalizaremos apenas um episódio do filme de Pedro Bial em que há supressão de alguns elementos do texto literário e reiteração de outros. Nesse sentido, suprime-se o estado de aparente loucura, enunciado no texto verbal por meio do ponto de vista da comunidade, que considera insana a coragem de Liojorge de enfrentar a fúria dos irmãos Dagobé ao ir ao enterro de Damastor, o qual matara em legítima defesa. Por outro lado, há a reiteração do estado de coragem do ator, implícito no texto rosiano, do ponto de vista do enunciador, em que Liojorge, mobilizado pela crença nos desígnios do transcendente, enfrenta Damastor para se defender e ainda vai a seu enterro para se solidarizar com seus irmãos. Tal estado de coragem se constrói figurativamente no texto audiovisual na cena de enfrentamento entre Damastor e Liojorge.

A cena descrita, no texto verbal, não chega a ocupar dez linhas e, no texto audiovisual, não ocupa mais que dois minutos. No entanto, em meio à pouca extensão textual muito se cria do ponto de vista do discurso e, desse modo, a tensão e o suspense são instaurados de maneiras distintas.

A surpresa, em ambos os textos, reside no rompimento com o esperado: do pacato não se espera o ímpeto. Focando-nos portanto, na noção de surpresa, queremos averiguar as relações que ocorrem entre a adaptação e o texto fonte, tendo em vista, como hipótese primeira a qual queremos demonstrar, que tanto no texto verbal quanto no texto audiovisual a surpresa nos leva à fé do sujeito, remodelada em coragem. Assim Bial mantém o tema comum a Rosa e se pode observar, ainda que de forma indireta, a equivalência entre os textos fonte e adaptado.

No conto, segundo o encadeamento figurativo que se constrói e que qualifica Liojorge, não se pode dele (um "lagalhé pacífico") esperar o ato que ousou executar. A surpresa, no texto verbal, redundará em um espanto para a comunidade tal que apenas a hipotética loucura do sujeito poderá explicar a sua atuação. Cria-se assim, no texto verbal, entre enunciador e enunciatário e narrador e narratário (duas instâncias distintas da enunciação) um mesmo contrato fiduciário, pois se crê, tanto do ponto de vista dos atores implicados no texto (ponto de vista enuncivo) quanto do ponto de vista do contrato instaurado entre enunciador e enunciatário do texto (ponto de vista enunciativo), na honestidade e no pacifismo de Liojorge. Vejamos as passagens do texto que constroem as características psicológicas de Liojorge e que nos levam a essa leitura:

Eis que eis: um lagalhé pacífico e honesto chamado Liojorge, estimado de todos [...] mas o quieto do rapaz [...] solitário em casa, resignado [...] sem ânimo de nenhum movimento [...] criminal de legítima defesa [...] (ROSA, 1988, p. 21-9, grifo nosso).

Como se pode perceber na isotopia que se constitui no texto, os estados de alma de Liojorge organizam-se em torno de humores átonos, aproximando-o quase de uma covardia perene. Sua inércia só é rompida diante da iminência da morte.

Já em outros trechos há a explicitação do ponto de vista dos expectadores do velório - da comunidade, portanto, ali presente -, segundo o qual Liojorge endoidecia de medo pela atitude intempestiva que tomara ao matar o facínora.

Liojorge sozinho em sua morada, sem companheiros, se doidava? Decerto, não tinha experiência de se aproveitar para escapar [...] devia de estar em o 
se agachar, ver-se em amarelas: por lá, borrufado de medo, sem meios, sem valor, sem armas. Já a alma era sufrágios! (ROSA, 1988, p. 29).

No entanto, ao aparecer repentinamente no velório de Damastor, deixa implícita sua coragem por acreditar na providência divina e em sua justiça. Esse é o ponto de vista do enunciador rosiano: fica implícito pelo seu estado de tranquilidade que estava certo de que nada the aconteceria, pois matara em legítima defesa.

Bom cristão, como o texto audiovisual irá confirmar, Liojorge confirma a inação como uma forma de vida, marcada por certo desvario e pela inconsciência ("varrido de todo o atinar") que o transfigura de algum modo, no texto verbal, como um inocente presumido, que poderia "declarar sua forte falta de culpa" (ROSA, 1988, p. 29). O conto constrói ainda a morte de Dagobé como involuntária:

Não tinha querido matar irmão de cidadão cristão nenhum [...] matara com respeito. O pálido pasmo. [...] De medo, esse Liojorge doidara [...] varrido de todo o atinar. (ROSA, 1988, p. 29-30).

Em todas as passagens, o narrador não define nem revela explicitamente a natureza de Liojorge, algo comum na obra de Rosa, apenas supondo e rondando seus desejos mais ocultos, enveredando, no entanto, sempre pelo estado de aparente loucura do sujeito ao matar gente tão poderosa, segundo o ponto de vista da comunidade. Na verdade, seu estado é de tranquilidade, do ponto de vista do enunciador, como consequência da fé nos desígnios transcendentais de que nada lhe aconteceria, na medida em que agiu em legítima defesa ao tirar a vida do facínora, construído, de maneira inversa à sua, como demoníaco e monstruoso.

Há, pois, no texto verbal a construção de sua humildade diante do morto e os valores cristãos que assume para si:

Seria assim de alma entregue, uma humildade mortal. Dirigiu-se aos três "Com Jesus!" [...] Tinha que fazer bem a sua parte: ter as orelhas baixadas [...] Feito um criado (ROSA, 1988, p. 31, grifo nosso).

Tais valores, ao contrário da inocência e da loucura, manter-se-ão equivalentes nos dois textos. E no texto verbal, Liojorge resta puro e inocente, pois sobre ele não há um juízo de valor que aponte, por exemplo, o premeditado do crime. Seu crime é expurgado tendo em vista a impureza que recobre Dagobé - impureza que, em Liojorge, por oposição, configura-se em pureza divina, no texto audiovisual, como veremos.

Assim, no texto audiovisual, a surpresa inicial revelará outra natureza de Liojorge, construindo como mentira e não mais como verdade a sua honestidade e o seu pacifismo. E embora a isotopia religiosa cristã se mantenha, é com outras cores que ela se dá a ver no texto fílmico. Vejamos, assim, antes de dar sequência à análise, uma segmentação possível das cenas da narrativa fílmica, em sua sequência original, em que Damastor Dagobé é morto por Liojorge: 
CASA, Vol.10 n.2, dezembro de 2012

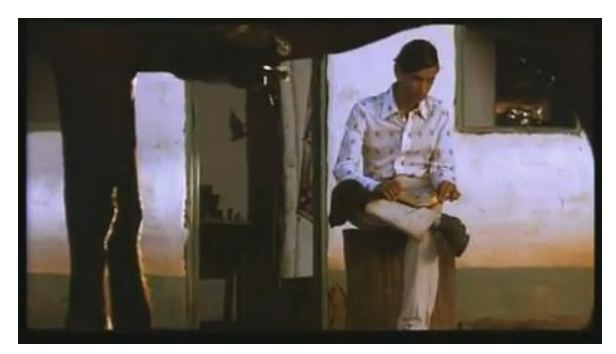

Figura 1

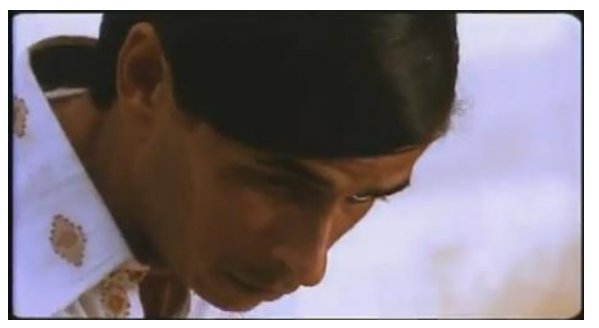

Figura 3

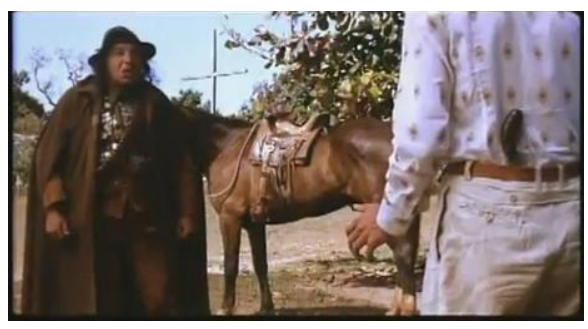

Figura 5

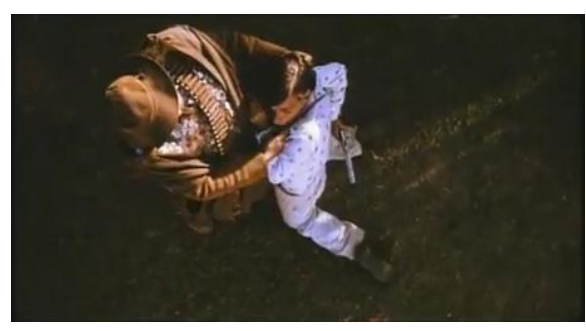

Figura 7

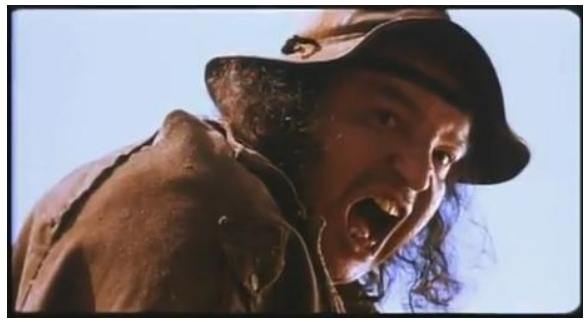

Figura 2

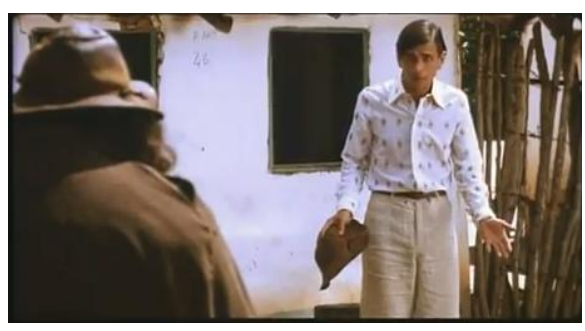

Figura 4

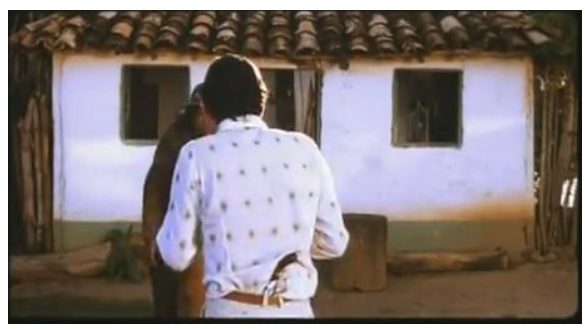

Figura 6

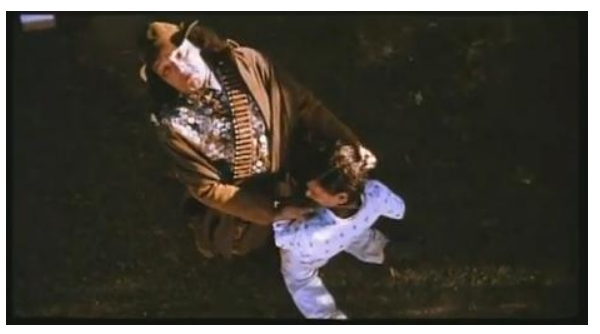

Figura 8

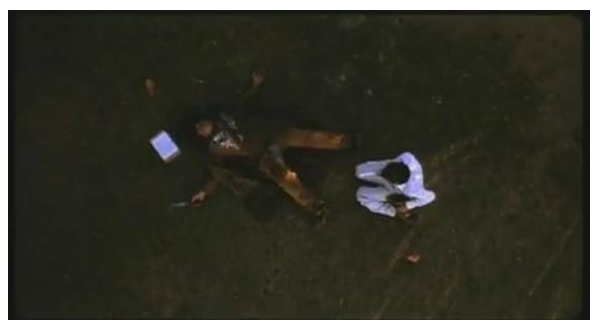

Figura 9

Disponível em: http://seer.fclar.unesp.br/casa 
Tanto no texto de Rosa quanto no De Bial, portanto, do ponto de vista do enunciador, Liojorge é construído como um rapaz aparentemente covarde, marcado pela inação, pela inocência e pela fé. Tal estado de covardia é, no entanto, apenas aparente, e essa corasgem é explicitada no texto visual, como veremos.

No texto audiovisual, a aparente covardia, a diminuição do sujeito, é construída graças às categorias de alto e baixo que se estabelecem desde o início, quando da entrada de Dagobé na cena em que Liojorge já está instaurado, sentado, lendo ${ }^{3}$. Liojorge aparece, no enquadramento da cena, abaixo do cavalo de Dagobé (Figura 1). Dagobé esbraveja, do alto do cavalo (Figura 2), e Liojorge mantém-se de cabeça baixa (Figura 3). Há na oposição entre alto e baixo aqui, somada à agressividade de Dagobé, a instituição de uma forma de humilhação e submissão que, como dissemos, mostrar-se-á mentirosa: Liojorge parece inferior, mas se revelará ser um ser superior, eis o engano. Dagobé assume assim, no alto, os valores disfóricos (demo, monstro, facínora), e Liojorge, no baixo, os valores eufóricos (santo, homem bom, vítima).

Quando os dois sujeitos se colocam na mesma altura é que surge a figura do cristão humilde e pacífico que se engrandece perante a figura de Dagobé (Figura 4) e há a revelação da arma de fogo de Liojorge e o engrandecimento proporcional da figura de Liojorge no enquadramento da cena: graças à proximidade da câmera, ele passa a ser maior que Dagobé, maior que o mal, que o humano violento que se apequena perante o humilde cristão(Figura 5). Dagobé então lhe diz, no texto audiovisual: "Não vai pedir a benção?" e Liojorge lhe responde: "Por Deus" (Figura 4). É então nesse momento que o próprio algoz revela a natureza divina de Liojorge, ao dizer: "Deus mesmo se vier pu [sic] sertão que venha armado" (figura 5). A partir da fala de Dagobé se constrói a natureza divina de Liojorge, pois o enquadramento da cena revela simultaneamente que ele carrega consigo uma arma na cintura, às suas costas. Do ponto de vista do fazer de Liojorge, a arma revela-se, assim, como instrumento de defesa, é objeto modal que lhe dá o poder-fazer, destruir o humano que representa o mal, porque violento. Do ponto de vista de um fazer divino, tendo Deus sido convocado à cena por Liojorge e Damastor ("Por Deus!" e "se Deus vier que venha armado"), a arma surge então como espécie de figura metonímica da força divina - quase um dedo de Deus - que, desafiado (que venha armado!), pune a maldade de Dagobé, valendo-se para isso de Liojorge.

A altura equivalente (Figuras 4, 5, 6) entre os dois atores indica o respeito (uma mesma hierarquização de valores, portanto), enunciado no texto verbal ("matara com respeito"), de Liojorge pela morte de Dagobé. Já na última cena, o lugar de Liojorge diante do corpo de Dagobé é o não-alto: Liojorge não retoma a posição do alto, nem chega ao baixo, em que a morte ocorre, mantém-se assim no meio termo, de joelhos (mais uma figura da religiosidade) como que resignado ("solitário em casa, resignado [...] sem ânimo de nenhum movimento [...] criminal de legítima defesa") diante do destino ao qual se conduziu. Foi assim que tudo começou na cena: sentado, lendo, resignado diante de sua própria condição, encontra aquele que matará. $\mathrm{O}$ que era eufórico no baixo (Liojorge e sua santidade), vai assim caminhar para o alto, e o disfórico do alto (Dagobé e sua malignidade) cai na direção do baixo. Vida e morte homologam-se assim, de forma contrária ao que se previa no início do texto, ao alto e ao baixo, respectivamente.

Como se vê, em ambos os textos a coragem se traveste em humildade e crença na justiça divina: aquele que clama por Deus ("Por Deus", diz Liojorge) tem a coragem de enfrentar o

\footnotetext{
${ }^{3}$ Embora não possamos afirmar categoricamente, Liojorge parece ler uma Bíblia.
} 
demônio. Todo o texto é marcado por uma isotopia religiosa que traveste Liojorge em espécie de guerreiro armado, tal qual o Santo Jorge, o mártir que acaba por matar o Dragão (o Dagobé, que tem na semelhança com o animal mítico mais que o conteúdo, repetindo-se assim, na expressão, duas oclusivas "d" e "g", a primeira alveolar sonora, e a segunda velar sonora).

É interessante observar que o mesmo papel temático do guerreiro armado de que é investido Liojorge já aparecera em "A hora e vez de Augusto Matraga" em que Matraga, o guerreiro cristão, mata Joãozinho Bem Bem para defender os humildes e impotentes.

Dagobé em momento algum descobre a arma e Liojorge, revelando-se, mais esperto, engana assim o vilão. Vale notar que anteriormente à morte de Dagobé se constrói para o enunciatário-espectador uma tensão de espera, pois não se contava com a sua reação perante a figura do todo poderoso Dagobé. No texto verbal tal tensão também se evidencia, mas em outro momento do texto: após o fazer de Liojorge, o enunciador explicita o ponto de vista da comunidade que esperava no velório, a vingança dos outros irmãos e considerou loucura a presença de Liojorge tranquilo e humilde no enterro. Convém ressaltar que, do ponto de vista do enunciador em ambos os textos a performance de Liojorge é construída como legítima defesa. Assim, em ambos os textos, verbal e visual, a crença na justiça divina é que move Liojorge é que lhe propicia o estado de tranquilidade. A aparente fragilidade do ator revela-se, por conseguinte, força que só a crença na justiça transcendental pode mobilizar, como se nota pelas figuras das cruzes e da bíblia que são redundantes no ambiente da cena da morte de Dagobé.

\section{Considerações finais}

A toada visual criada no texto fílmico, o engano e a alteração axiológica (o baixo pelo alto, o alto pela baixo, o bem e o mal construindo-se alternadamente), o caráter mítico e atemporal do texto, são, visivelmente, análogos aos processos textuais e discursivos construídos no texto fonte.

Embora em meio a coerções formais distintas, o texto adaptado mantém o recurso à metáfora como aquele empregado por Rosa, mantém a força da materialidade do texto, na sua expressão, na condensação que atualiza o fragmento como estratégia discursiva, na reiteração do universo de valores em que a aparente covardia, travestida de humildade do ator, revela-se na verdade, coragem mobilizada pela fé religiosa.

Vê-se assim como os textos, ainda que em outros formatos, conseguem ser em grande medida equivalentes do ponto de vista dos sentidos que estão em causa na tradução/transcodificação semiótica. E, mais, graças à análise, podemos observar a seleção isotópica orquestrada por Pedro Bial na tessitura de seu filme: lá estão todos os oximoros, a mítica, a epifania, e a organização de um mundo de base religiosa que revela a dimensão transcendente do homem. Assim, em ambos os textos o divino manifesta-se no próprio homem: é o homem que adquire estatura quase bíblica, tornando-se em certa medida iluminado, como revela a imagem de Liojorge ajoelhado no episódio final da cena (figura 09) do filme que acaba por reiterar a isotopia temática da submissão do homem aos desígnios transcendentais, que também perpassa o texto literário rosiano. 


\section{REFERÊNCIAS}

ABRIATA, V.L.R. Outras historias and Primeiras Estorias: an interdiscoursive dialogue. In: Annales du 8 Congrès de l'Association Internationale de sémiotique, Lyon, 2007, p. 1-6.

BOSI, A. História concisa da literatura brasileira. São Paulo: Cultrix, 2006.

. "Céu, Inferno". In: BOSI, A. Céu, inferno. São Paulo: Ática, 1988.p. 10-32.

BIAL, P. Outras estórias. Rio de Janeiro, 1999. Disponível em :<http://www.youtube.com/ watch?v=n6F8-rsKTWw>. Último acesso em: 01 de agosto de 2012.

DINIZ, T. F. N. Tradução intersemiótica: do texto para a tela. Cadernos de Tradução, número 3, Florianópolis, 1998. p. 313-338.

2003.

. Literatura e cinema: da semiótica à tradução cultural. Ouro Preto: Editora UFOP,

FIORIN, J. L. Semiótica e comunicação. In: DINIZ, M.L.V.P. ; PORTELA, J.C. (Orgs.). Semiótica e Mídia: textos, práticas, estratégias. Bauru: Unesp/Faac, 2008, p. 75-92.

FONTANILLE, J. Sémiotique et littérature. Essais de méthode. Paris: PUF, 1999a.

GREIMAS, A.J.; COURTÉS, J. Dicionário de semiótica. São Paulo: Contexto, 2008.

LORENZ, G. Diálogo com Guimarães Rosa. In: COUTINHO, E. de F. (Org.) Guimarães Rosa. Rio de Janeiro: Civilização Brasileira/INL, 1983, p.62-97. (Fortuna Crítica, 6).

POUND, E. Abc da Literatura. São Paulo: Cultrix, 1997.

ROSA, J. G. Grande sertão: veredas. Rio de Janeiro: José Olympio, 1976.

. Primeiras estórias. Rio de Janeiro: Nova Fronteira, 1988.

SCHWARTZMANN, M.N. Cartas marcadas: Prática epistolar e formas de vida na correspondência de Mário de Sá-Carneiro. 2009. 293 p. Tese. (Doutorado em Linguística e Língua portuguesa) - Faculdade de Ciência e Letras de Araraquara, Universidade Estadual Paulista, Araraquara.

PEREIRA, H.B.C. As adaptações das Primeiras estórias de João Guimarães Rosa para o cinema. Ipotesi, Juiz de Fora, v. 13, n. 1, p. 117 - 127, jan./jul. 2009.

Recebido em: 27/07/12

Aprovado em: 15/10/12 